\title{
Influencing highly religious undergraduate perceptions of evolution: Mormons as a case study
}

\author{
Katie F. Manwaring ${ }^{*}$, Jamie L. Jensen, Richard A. Gill and Seth M. Bybee
}

\begin{abstract}
Background: Students frequently hold an incorrect view of evolution. There are several potential barriers that prevent religious students, specifically, from engaging evolutionary theory in the classroom. This study focuses on two hypothesized barriers on learning evolutionary theory in a highly religious model population, specifically members of The Church of Jesus Christ of Latter-day Saints (LDS or Mormon): (1) religious views stemming from incorrect or inadequate understanding of the Mormon church's neutral stance on evolution and (2) misunderstanding of the theory of evolution. The LDS population at Brigham Young University provides the ideal setting for studying evolution education among religious individuals in a controlled environment. To ascertain the prevalence and effect of these barriers, we measured the relationship between acceptance of evolution and knowledge of evolution, religiosity, and understanding of religious doctrine on evolution in introductory non-majors biology courses. Additionally, we measured the effect of including a discussion on religious doctrine in the classroom. Students in all sections, except for one control section, were taught a unit on evolution that included a discussion on the neutral LDS doctrine on evolution. Data was gathered pre, post, and longitudinally.
\end{abstract}

Results: Our data demonstrate a positive relationship between knowledge and acceptance of evolution, a positive relationship between understanding of religious doctrine and acceptance of evolution, and a negative relationship between religiosity and acceptance of evolution. Additionally, when an in-class discussion was held addressing the LDS doctrine on evolution students became more accepting of the principles of evolution.

Conclusions: These data provide compelling evidence that an accurate understanding of their religious doctrines and knowledge of evolution can lead to greater acceptance of the basic concepts of evolution among highly religious students.

Keywords: Education, Evolutionary misconceptions, Biology, Religion, Religiosity, STEM, LDS, Mormon

\section{Background}

Evolution is the change in populations over time that has lead to the diversity of life on earth (Mayr 2001). Examining the world in the context of evolution is central to understanding the biological patterns and complexity found in nature. For example, the anatomical similarities shared by all mammals are best explained by the principle of common ancestry and the process of natural selection. Understanding (and accepting) the theory

*Correspondence: katiefager@gmail.com

Department of Biology, 4102 LSB, Brigham Young University, Provo, UT 84602, USA of evolution leads to greater improvements in agriculture, medicine, political decisions, etc. The United States falls short in understanding and acceptance of Darwinian evolution compared to other countries (Miller et al. 2006; Newport 2012). In general, US students have a fragmented and incorrect view of the theory (Rees 2007; Brewer and Gardner 2013). They also appear to be hindered in understanding and acceptance of evolution due to misconceptions (Battisti et al. 2010; Hawley et al. 2011; Foster 2012). This common rejection of evolution by the general population impedes the ability of students to truly understand and embrace nature (including their 
place in it) and biodiversity. While there are many papers that address various factors influencing acceptance of evolution (Sherkat 2011; Wiles and Alters 2011; Heddy and Nadelson 2013, Wiles 2014; Carter and Wiles 2014), we will focus on three primary variables: (1) ignorance/ lack of knowledge about evolutionary theory, (2) religiosity and (3) understanding of religious doctrine.

Regarding the first variable, research has shown that students harbor many misconceptions concerning the theory of evolution (Nehm and Schonfeld 2007; Battisti et al. 2010; Hawley et al. 2011; Foster 2012). These misconceptions range from not understanding the specific details about foundational principles (e.g., genetic drift) to not comprehending the larger scale processes (e.g., natural selection) and what evolution is in general (Rees 2007; Halverson 2010; Andrews et al. 2012; Athanasiou and Mavrikaki 2013; Brewer and Gardner 2013). To better understand how to aid students in overcoming these misconceptions, numerous quantitative assessment tools have been developed that differentiate elements of evolutionary theory in order to identify underlying fallacies that fuel misconceptions (Anderson et al. 2002; Rutledge and Sadler 2007; Cotner et al. 2010; Price et al. 2014). Many of these instruments are measurements of knowledge, which take into consideration the number of misconceptions students have (e.g., Knowledge of Evolution Exam; Cotner et al. 2010).

The relationship between knowledge and acceptance of evolution has been widely studied, but no clear association has emerged (Rissler et al. 2014). Robbins and Roy (2007) found change in evolution acceptance after limited instruction, while others found that change in acceptance associated with increased knowledge happened only for those who were initially undecided on the topic (Wilson 2005; Ingram and Nelson 2006). Conversely, others have found that improvement in knowledge does not lead to increased acceptance of evolution (Lawson and Worsnop 1992; Crawford et al. 2005; Cavallo and McCall 2008). Interestingly, Nadelson and Sinatra (2010) showed that acceptance of evolution can increase even when knowledge does not. When the relationship between knowledge and acceptance of evolution has been researched outside of the US, where there is less tension between evolution and religion, studies have found that increased knowledge led to increased acceptance of evolution (Akyol et al. 2010; Kim and Nehm 2011; Ha et al. 2012).

The second variable we consider is religion. Given that the positive relationship between knowledge and acceptance of evolution may be diminished by religion, we discuss two underlying mechanisms concerning religion that influence acceptance of evolution: religiosity and understanding of religious doctrine (Andersson and
Wallin 2006; Coyne 2012; Heddy and Nadelson 2013; Rissler et al. 2014). Religiosity, as addressed herein, is considered a commitment to respective religious practices centering on a belief in a higher being. Several studies show that the more religious students are, the less likely they are to understand evolution or have positive attitudes toward the topic (e.g., Lawson and Worsnop 1992; Meadows et al. 2000; Barnes et al. 2009; Moore et al. 2011). Coyne (2012) found that resistance to evolution is "uniquely high" in the US, and it is the high religiosity of the US that drives this opposition. For example, $60 \%$ of the general US public now accepts that humans have evolved (Masci 2009), yet up to $92 \%$ of some religious groups still reject human evolution (Miller 2008). This suggests that religiosity is a large part as to why the US struggles in its acceptance of evolution.

The third variable we consider that influences acceptance of evolution is an understanding of respective religious doctrines (core set of beliefs/practices) concerning evolution. It may be difficult for religious individuals to accept the theory of evolution when they feel that the theory conflicts with the doctrine of their religion. Some religions do have doctrine that openly rejects the theory of evolution (Weeks 2014; Affirmation of Creation 2004). However, many religious groups do not have an inherent conflict between their doctrine and the theory of evolution, either having a neutral or affirmative stance toward evolution (Colburn and Henriques 2006; Kohut et al. 2009). Yet, many individuals who claim membership in these "accepting" religions still feel that evolution conflicts with their religious and therefore personal beliefs (Reiss 2009; Burton 2011; Hawley et al. 2011). It may be that individuals are not aware of their respective religion's overall view of evolution. Christian denominations vary greatly in acceptance of evolution. For example, Catholics are the most accepting as compared to other Christian denominations (Miller 2008). The current general acceptance among Catholics seems to date to 1950 when Pope Pius XII stated that the theory of evolution does not conflict with the beliefs of the Catholic Church (Mislin 2012). The majority of the doctrines from other denominations also do not directly conflict with evolutionary theory (Ludlow 1992; Religious Groups' Views on Evolution 2009; McKenna 2014). Yet, a survey conducted by the Pew Forum showed the majority of people belonging to Christian denominations reject the theory of evolution (Miller 2008). The Catholic Church is just one example of a religion whose doctrine is neutral, if not supportive, toward evolution yet many of its members still reject the theory. These results suggest that perhaps the majority of Christians who reject evolution do so on the basis of misconceptions and/or a misunderstanding of their own religious doctrine. 


\section{An example from Latter-day Saints (LDS)}

In order to investigate the relationship between knowledge and religiosity with acceptance of evolution, we chose to study a highly religious population. The LDS population provides an ideal model for studying the acceptance of evolution because $78 \%$ of the overall church membership is opposed to evolution (Miller 2008) even though there is no doctrine that openly rejects it. The LDS church is the fourth largest Christian denomination in the US and has over 15 million members worldwide.

Regarding the origin of humans, the presiding body of the LDS church has made three official statements (see methods below; Smith et al. 1909; Smith et al. 1910; Grant et al. 1925). There have been no official doctrinal statements addressing the theory of evolution. The clearest and most recent statement on evolution formally associated with the LDS church is in the Encyclopedia of Mormonism, which is approved by BYU's board of trustees (including the President of the church). Statements from this article assert that the LDS religion "is not hostile to real science...that which is demonstrated, we accept with joy" and, "the scriptures tell why man was created but they do not tell us how" (Ludlow 1992). From these statements it is clear that the LDS religion maintains strict belief in God as the creator. However, the church does not specify how the creation was accomplished, nor does it confirm or deny the potential for evolutionary creation (i.e., theistic evolution), and the language of these existing statements make allowances for scientific interpretation. Even though LDS church doctrine holds a neutral stance towards evolution, the vast majority of LDS members reject the theory of evolution (Miller 2008).

The LDS student population at Brigham Young University (BYU) is an ideal system to investigate the questions outlined below because the population is relatively homogenous in religious commitment, moral views, age and life experience. Over $98 \%$ of BYU students are LDS. The student body is ranked as the most religious in the US (Hafiz 2014), and offers a unique model for researching evolution education. The views of the BYU student body towards evolution also reflect those of the general Mormon population (see discussion). The LDS church sponsors BYU and urges that course subjects, including the theory of evolution, be taught with the same subject matter, rigor and data as other universities across the US (BYU Mission Statement; see Additional file 1: Appendix C).

\section{Research questions}

This research examines the influence of three factors influencing LDS student acceptance of evolution: knowledge of evolution, religiosity, and comprehension of the neutral LDS position on evolution. We have four main research questions: (1) Is there a relationship between conceptual understanding of evolutionary theory and acceptance? (2) Is there a relationship between religious commitment (religiosity) and student acceptance of evolution? (3) Does an understanding of LDS doctrine concerning evolution affect the acceptance of evolution among LDS students? (4) Can instructors influence LDS student acceptance of evolution by helping them understand the specific religious doctrine on evolution?

\section{Methods}

Approval from the BYU IRB was obtained for this research prior to data collection (IRB X110455).

\section{Study population}

The LDS population at BYU provides the ideal setting for studying evolution education among religious individuals in a controlled environment. Brigham Young University is a LDS sponsored private institution that promotes teaching religious principles in every subject. Because discussion of religion is encouraged in the classroom, we have controlled the presence of religious discussion in general biology classrooms and measured the effects of such a discussion on student knowledge and acceptance of evolution.

\section{Sampling}

We sampled undergraduate students enrolled in introductory biology for non-majors at BYU, Provo, UT.

We administered surveys measuring conceptual understanding, religiosity, understanding of religious doctrines, and student acceptance of evolutionary theory among LDS students. Over 1500 complete responses were collected over the course of two semesters from two sections during winter (January-April) and 11 sections during fall (September-December) 2013 (see Table 1). All students surveyed were LDS and enrolled in an introductory course for non-majors that included a unit on evolution. We recognize that the results reported herein may be influenced by several factors such as curriculum design. However, our large sample size should serve to mitigate many of these issues. The composition of the introductory biology sections was $58 \%$ freshman, $25 \%$ sophomores, $11 \%$ juniors, and $6 \%$ seniors as the introductory biology course is a general education requirement and can be taken at any point during the undergraduate studies. To measure retention of knowledge and acceptance, a longitudinal survey was sent to all students 5-7 months after completing the course.

\section{Course intervention and control group}

To determine if we could influence acceptance by targeting misconceptions about LDS religious doctrine, we used a quasi-experimental design comparing sections 


\section{Table 1 Number of complete responses to semester and follow-up surveys}

\begin{tabular}{ll}
\hline Semester surveys & Six-month follow-up survey \\
\hline Winter 2013 & September 2013 \\
$N=234$ & $N=72(30.8 \%)$ \\
Fall 2013 & July 2014 \\
$N=863$ & $N=201(23.3 \%)$ \\
\hline
\end{tabular}

Fall 2013: $46 \%$ response rate

where religious doctrine was addressed (treatment condition, $\mathrm{n}=1104$ ) to a section in which it was not addressed (control condition, $\mathrm{n}=101$ ). We administered the same dependent measures to each section and compared them.

Teaching the LDS stance on evolution During the course of the semester, all but one of the introductory biology sections (control) included at least part of one lecture that presented and discussed the official church stance on human origins via the "BYU Evolution Packet" (http://www.ndbf.net/010.pdf). This packet presents the official LDS church statements regarding human origins and is comprised of an introduction to the packet and its history, a series of statements made by the presiding body of the church, and a statement from the Encyclopedia of Mormonism. During this lecture, designed more like a discussion, students were allowed to ask questions and make comments. This formal discussion took up to one lecture period (50-75 $\mathrm{min}$ ); there are 28 or 42 lecture periods (2100 $\mathrm{min}$ ) for introductory biology during a BYU semester, depending on whether a class meets two or three times a week. The control treatment had access to the BYU Evolution Packet if they desired to look it up on their own, but no time was set aside to address or discuss it. There is no way of knowing whether students in the control section accessed it or not. During the time the treatment sections devoted to discussion of the official LDS stance on evolution, the control section continued with standard evolution content.

Teaching evolution Students in both the treatment and control groups were taught a unit on evolution (4-8 lectures). Specifically, students were given evidences (biological observations) explained by evolution and were exposed to a variety of evidences such as morphological similarities across organisms, vestigial traits, fossils, a common genetic code, phylogenetics, etc. They were also taught about the processes of natural selection, genetic drift, gene flow, non-random mating and mutation as mechanisms for evolution. Overall, the unit on evolution for both the treatment and control groups represented the standard topics and materials covered in a typical introductory biology text.

\section{Instruments}

Students in both treatments were sent links to the following web-based surveys via email from K. Manwaring (author). Incentives for survey response depended on the instructor and included assignment credit or extra credit. Feedback on surveys was not provided to students after any of the administrations of the survey.

1. The Knowledge of Evolution Exam (KEE; Cotner et al. 2010) The KEE was used to test our first research question, as it is a measure of conceptual knowledge. This instrument was developed as a concept inventory for evolution. Student answers were scored dichotomously (correct or incorrect) and then summed for this ten-item instrument. This instrument was administered as a pretest at the beginning of the semester and a posttest at the end. It was also included in the longitudinal survey.

2. Religiosity and Demographic Survey (Additional file 1: Appendix A) The religiosity instrument was used to test our second question, which addresses religious factors that influence acceptance of evolution. For this survey, students answered general demographic questions as well as questions regarding the frequency of their religious practices. Questions regarding religiosity $(7,9,12,16,19)$ each had five response categories and were summed to provide an overall measure of religiosity. A factor analysis was performed on these five items for validation that these questions measure the same variable in respondents. The remaining questions, which differed in the number of response categories, were scored individually and used as grouping variables in analyses. This was administered once during the semester.

3. Understanding of the LDS Stance on Evolution (ULSE; Additional file 1: Appendix B) After conducting surveys during the winter 2013 semester, we saw a need to measure student understanding of the LDS stance on evolution. Thus, a new instrument was created and administered during the fall 2013 semester. It is comprised of questions assessing student understanding of the LDS stance on evolution (ULSE). This was used to test our third question regarding students understanding of their respective religious doctrine regarding evolution. This is a 3-item instrument, with six response categories for each question (strongly disagree to strongly agree; Additional file 1: Appendix B). A factor analysis was performed on these three items for validation that they measure the same variable in respondents (that is understanding of the LDS stance on evolution). Scores were computed by summing responses to each individual question. This instrument was administered as a pre- 
test at the beginning of the semester and a posttest at the end. It was also included in the longitudinal survey for the fall 2013 respondents.

4. Measurement of Acceptance of the Theory of Evolution (MATE; Rutledge and Sadler 2007) We used this survey as our dependent measure-a measure of the acceptance of evolution. This survey addresses attitudes toward topics such as the scientific validity of evolution, human evolution, evidence of evolution, and the scientific community in general. This 20-item instrument (with six response categories ranking from strongly disagree to strongly agree) was administered as a pretest at the beginning of the semester and a posttest at the end. It was also included in the longitudinal survey. Though the MATE has been previously validated (Rutledge and Sadler 2007), a factor analysis was performed on the MATE, per the suggestion of Wagler and Wagler (2013) to validate an instrument each time it is administered to a new unique population. Scores were computed by summing responses to each individual question. Totaled scores were assigned a relative category (see Table 2) as done in Wiles and Alters (2011).

\section{Analyses}

Using SPSS v. 21 [IBM, (Armonk, NY)], we ran a series of traditional statistical analyses to address our research questions. First, to determine which factors (conceptual understanding, religious factors, or doctrinal understanding) predicted an overall acceptance of evolution, we ran a general linear model (GLM) multiple regression analysis with the KEE, demographic factors, our religiosity measure, and the ULSE as predictors of the MATE (see Table 3 for complete list of variables entered into model). Items were entered stepwise into the model with an entry of a $0.05 p$ value and a removal of a 0.10 p-value.

To analyze change in knowledge of evolution and acceptance of evolution we compared pretest, posttest, and longitudinal scores on the KEE and the MATE, using repeated measures ANOVAs and the frequency distribution of the relative MATE categories. To measure an increase in understanding of religious doctrine and acceptance of evolutionary theory, we compared pretest, posttest, and longitudinal scores on the ULSE and MATE using repeated measures ANOVAs.

To assess the success of discussing religious doctrine in clarifying understanding of doctrinal stance and increasing acceptance of evolution, we compared the change in evolution knowledge (KEE), doctrinal understanding (ULSE) and acceptance of evolution (MATE) between treatment and control sections using an independent one-way ANOVA analysis.

\section{Results}

\section{Reliability and validity of scales}

From our exploratory factor analysis of the religiosity items, we recovered one factor with an eigenvalue much

Table 2 Categories of relative acceptance of evolution

\begin{tabular}{|c|c|c|c|}
\hline Relative acceptance category & MATE score & $\begin{array}{l}\text { MATE \# } 1 \text { response } \\
\text { breakdown }\end{array}$ & $\begin{array}{l}\text { MATE \#2 response } \\
\text { breakdown }\end{array}$ \\
\hline Very high acceptance & $107-120$ & $61(5.5 \%)$ & $266(23.8 \%)$ \\
\hline High acceptance & $92-106$ & $192(17.2 \%)$ & $367(32.9 \%)$ \\
\hline Moderate acceptance4 & $78-91$ & $357(32.0 \%)$ & $282(25.2 \%)$ \\
\hline Low acceptance & $64-77$ & $327(29.3 \%)$ & $158(14.1 \%)$ \\
\hline Very low acceptance & $20-63$ & $117(10.5 \%)$ & $31(2.8 \%)$ \\
\hline
\end{tabular}

MATE \#1 and MATE \#2 response breakdowns represents the number of students who fell in each category at the beginning and end of the semester, respectively

Table 3 Predictors of initial acceptance of evolution

\begin{tabular}{|c|c|c|c|c|c|c|}
\hline \multirow[t]{2}{*}{ Final model } & \multirow[t]{2}{*}{$\begin{array}{l}\text { Correlation } \\
\text { with MATE (R) }\end{array}$} & \multicolumn{2}{|c|}{$\begin{array}{l}\text { Unstandardized } \\
\text { coefficients }\end{array}$} & \multirow{2}{*}{$\begin{array}{l}\text { Standardized } \\
\text { coefficients } \\
\text { Beta }\end{array}$} & \multirow[t]{2}{*}{$\mathbf{t}$} & \multirow[t]{2}{*}{ Significance } \\
\hline & & B & Std. error & & & \\
\hline ULSE \#1 & 0.475 & 1.844 & 0.137 & 0.419 & 13.462 & 0.000 \\
\hline KEE \#1 & 0.312 & 1.345 & 0.209 & 0.199 & 6.438 & 0.000 \\
\hline Controversial topics & 0.250 & 2.415 & 0.425 & 0.172 & 5.677 & 0.000 \\
\hline Religiosity scale & -0.157 & -0.967 & 0.190 & -0.154 & -5.082 & 0.000 \\
\hline
\end{tabular}

Excluded (non-significant) variables are: instructor, class day, time of class, gender, biology experience, year in college, family income, parent education, health, parent religiosity, involvement in clubs, church mission experience, and family religious affiliation 
above the rest. This factor explained $46.45 \%$ of the variance. The scale had an acceptable level of internal consistency, as determined by a Cronbach's alpha of 0.677.

From our exploratory factor analysis of the ULSE instrument, only one factor was extracted. This factor explained $62.29 \%$ of the variance. The scale had an acceptable level of internal consistency, as determined by a Cronbach's alpha of 0.693.

From our exploratory factor analysis of the MATE items, we recovered four factors with an eigenvalue above 1 . However, the first factor explains $46.84 \%$ of the variance and the next factor only explains an additional $6.97 \%$. In addition, when examining the factor rotation, all items loaded highest on the first factor with all loadings exceeding 0.5 , with the exception of one, which had a loading of 0.488 . The scale had a high level of internal consistency, as determined by a Cronbach's alpha of 0.915 .

\section{Change in evolution acceptance}

From a frequency distribution, the majority of students had moderate to low acceptance of evolution at the beginning of the semester (see Fig. 2). By the end of the semester there was a significant gain in evolution acceptance ( $<<0.001$; see Fig. 3 ), which resulted in the majority of students having high acceptance of evolution.

\section{Predictors of initial acceptance}

Our results show that knowledge of evolution (KEE), understanding of LDS doctrine (ULSE) and religiosity significantly predict initial acceptance of evolution [MATE; $F(4,748)=91.530, p<0.001$; see Table 3]. Only religiosity and evolution acceptance were negatively correlated, with a Pearson Correlation of $-0.157(p<0.001$, see Table 3 for additional statistics). All slopes were fixed as section type (i.e., control vs. treatment) was not taken into consideration for this part of the analyses. See Table 3 for additional factors entered in the GLM regression and final model outcome.

\section{Relationship between knowledge and acceptance}

From the GLM multiple regression analysis, knowledge of evolutionary theory (KEE score) was a significant predictor of initial attitude toward evolution (see Table 3). For every point gained in understanding (on a 10-point scale) acceptance increased by an average of 1.35 (on a 120-points scale).

A repeated measure ANOVA tested for significant gains over time in student knowledge and in student acceptance of evolution as well as for an interaction between KEE and MATE scores. Students demonstrated significant gains in knowledge [KEE; $F(1,1051)=70.64$, $p<0.001$; see Table 4 for averages] and in acceptance of evolution [MATE; $F(1,1053)=1009.45, p<0.001$; see Table 4 for averages]. The interaction between the gains in the MATE and the gains in the KEE was also significant $[F(1,1050)=945.76, \mathrm{p}<0.001]$, meaning that students who increased in knowledge (KEE) the most during the semester saw the greatest gains in acceptance of evolution (MATE).

A repeated measure ANOVA comparing the longitudinal survey to the post semester survey showed there was a significant decrease in knowledge over the 5-7 months after the course [KEE; $F(1,283)=28.9, p<0.001$; see Table 5]. There were no significant changes in the MATE between the post semester survey and longitudinal survey.

\section{Relationship between understanding of religious doctrine and acceptance}

From the GLM multiple regression analysis, another predictor of acceptance of evolution (MATE score) was degree of understanding of the LDS stance on evolution (ULSE score; see Table 3). For every 1-point increase in understanding of doctrine (on an 18-point scale), the MATE increased 1.84 points (on a 120-point scale).

A repeated measure ANOVA detected significant gains over time in student understanding of the LDS stance on evolution [ULSE; $F(1,820)=2427.41, p<0.001$; see

Table 4 Descriptive statistics of within semester results

\begin{tabular}{lcccccc}
\hline & N & Min & Max & Mean & Std. dev. & Significance (2-tailed) \\
\hline MATE \#1 & 1054 & 37 & 120 & 81.09 & 14.74 & $<0.001$ \\
MATE \#2 & 1104 & 43 & 120 & 93.75 & 15.72 & $80.20-81.98$ \\
KEE \#1 & 1053 & 0 & 10 & 6.14 & 1.964 & $<0.001$ \\
KEE \#2 & 1103 & 0 & 10 & 6.61 & 1.959 & $6.02-6.25$ \\
ULSE \#1 & 821 & 3 & 18 & 12.21 & 3.075 & $<0.001$ \\
ULSE \#2 & 869 & 3 & 18 & 13.79 & 2.91 & $12.00-12.42$ \\
\hline
\end{tabular}

Significance and $95 \% \mathrm{Cl}$ are results of t-tests comparing the pre to post survey averages of each instrument

$\# 1$ indicates the responses collected at the beginning of the semester (pre survey)

$\# 2$ indicates the responses collected at the end of the semester (post survey) 
Table 5 Descriptive statistics of students that responded to the longitudinal survey

\begin{tabular}{|c|c|c|c|c|c|c|}
\hline & $\mathbf{N}$ & Min & Max & Mean & Std. dev. & $95 \%$ Confidence interval \\
\hline MATE \#1 & 273 & 40 & 120 & 83.32 & 15.60 & $77.67-81.84$ \\
\hline MATE \#2 & 273 & 50 & 120 & 95.26 & 15.14 & $88.42-92.65$ \\
\hline MATE \#3 & 273 & 50 & 120 & 95.52 & 15.90 & $88.25-92.75$ \\
\hline KEE \#1 & 273 & 0 & 10 & 6.27 & 1.88 & $5.86-6.39$ \\
\hline KEE \#2 & 273 & 0 & 10 & 6.81 & 1.93 & $6.31-6.88$ \\
\hline KEE \#3 & 273 & 0 & 10 & 6.48 & 1.87 & $6.11-6.67$ \\
\hline ULSE \#1 & 177 & 8 & 18 & 13.79 & 2.40 & $13.44-14.16$ \\
\hline ULSE \#2 & 177 & 7 & 18 & 14.21 & 2.63 & $17.56-18.46$ \\
\hline ULSE \#3 & 201 & 3 & 18 & 13.52 & 3.13 & $17.62-18.67$ \\
\hline
\end{tabular}

Acceptance of evolution and understanding of LDS doctrine on evolution remained higher after the semester is over while knowledge of evolution decreased \#1 indicates the responses collected at the beginning of the semester

$\# 2$ indicates the responses collected at the end of the semester

\#3 indicates the responses collected in the longitudinal survey

Table 4 for averages]; however, this increase was not consistent across sections (discussed below for the control section). The interaction between the gains in the MATE and the gains in the ULSE was also significant $[F(1$, $820)=213.94, \mathrm{p}<0.001]$, indicating that students who increased most in the ULSE saw the greatest gains in the MATE as well.

A repeated measure ANOVA comparing the longitudinal survey to the post semester survey showed there was no significant change in understanding of the LDS stance on evolution (ULSE; Table 5).

\section{Effectiveness of treatment (discussion of LDS stance on evolution)}

A one-way ANOVA showed that students who participated in a discussion about religious doctrine had significantly higher average gains in acceptance (MATE) than students in the control section where a discussion was not held $[F(1,1052)=26.30, p<0.001$; see Fig. 1a, b). In addition, the students participating in the discussion had a greater average gain in understanding of LDS doctrine (ULSE) than students who did not $[F(1,820)=15.19$, $p<0.01$; see Fig. 1b]. Interestingly, these gains in acceptance and understanding of religious doctrine did not correspond to an increase in understanding of evolutionary theory. Students in the section without discussion of LDS doctrine gained more knowledge on average than sections that did have a discussion $[F(1,1050)=6.59$, $p<0.01$; see Fig. 1c].

\section{Discussion}

This study explores three variables and their possible relationship with acceptance of evolution among religious students. These variables are: knowledge of evolution, religious practices, and knowledge of religious doctrine.
In addition, we measured changes in the acceptance of evolution following a discussion dedicated to LDS doctrine and evolution.

Overall, students increased substantially in their acceptance of evolution over the course of the semester(see Fig. 3). At the beginning of the semester, only $22.7 \%$ of students were highly supportive (accepting) of evolution, while $39.8 \%$ of students were dismissive (Fig. 2). The remaining students fell into the moderately accepting category. Thus, the BYU student body is representative of the overall US LDS church membership regarding acceptance of evolution (22\% acceptance rate; Miller 2008). While the perceived disagreement between religion and evolution continues, educators should be encouraged by student ability to learn and change perspective. By the end of the semester $56.7 \%$ of students were very highly accepting or highly accepting of evolution, a significant increase of $34 \%(p<0.001)$ from the beginning of the semester. Thus, even though a low percentage of students initially accepted evolution at a high level, there were even fewer students who dismissed it by the end (see Fig. 2).

We also found that with explicit instruction, there is a significant increase in knowledge of evolution. This is a logical and expected result (Cotner et al. 2009; Kim and Nehm 2011; Moore et al. 2011). In general, students respond well (via increase in knowledge) when evidence of evolutionary theory is provided and specific misconceptions are targeted (Wiles 2014; Moore et al. 2011). Obviously educating students on evolution will improve their understanding of it, but some studies show this is only true for the least religious students (Moore et al. 2011; Kahan 2015; Rissler et al. 2014). Our data show no significant relationship between religiosity and gains in knowledge of evolution. Instead, students made 


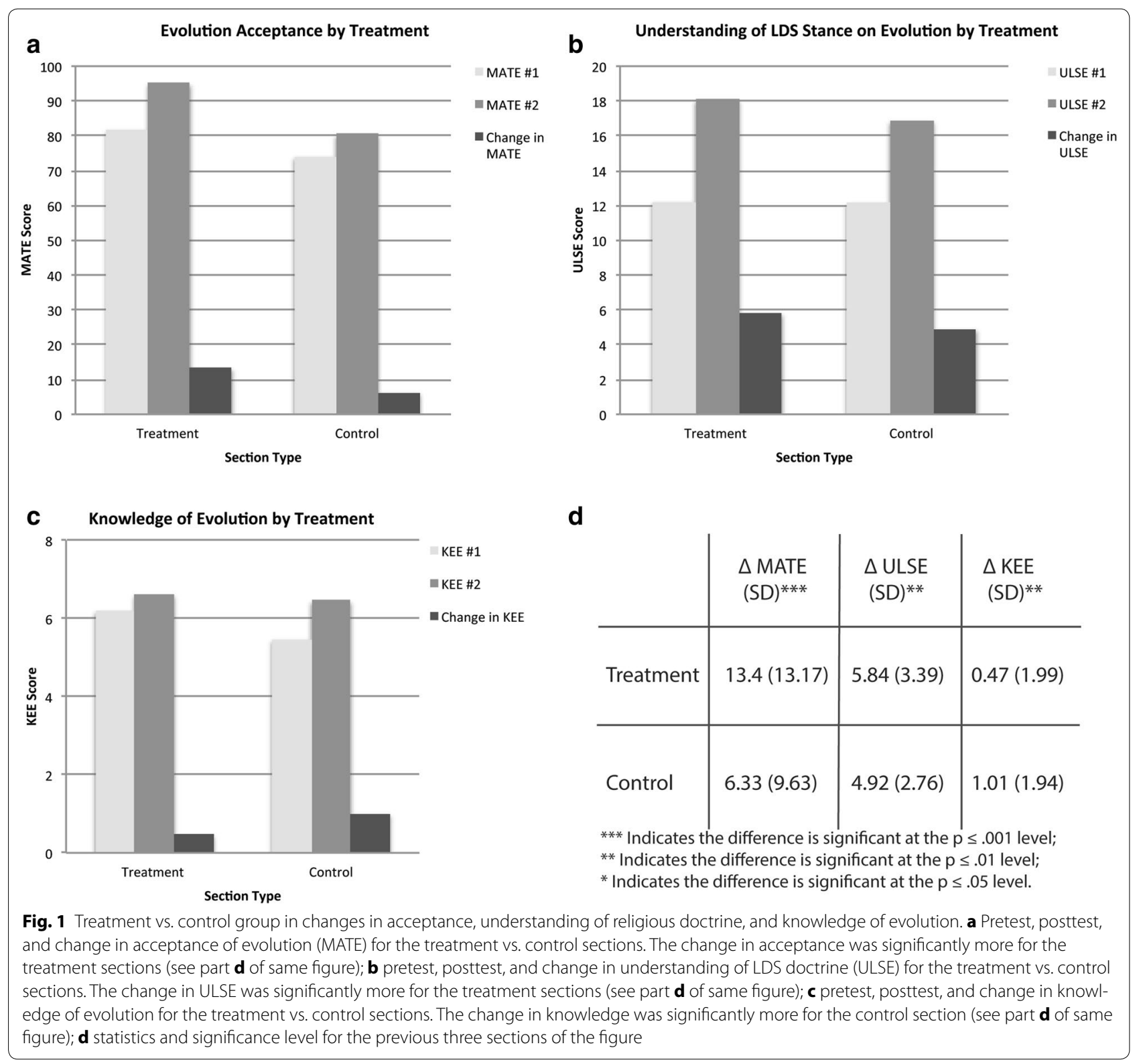

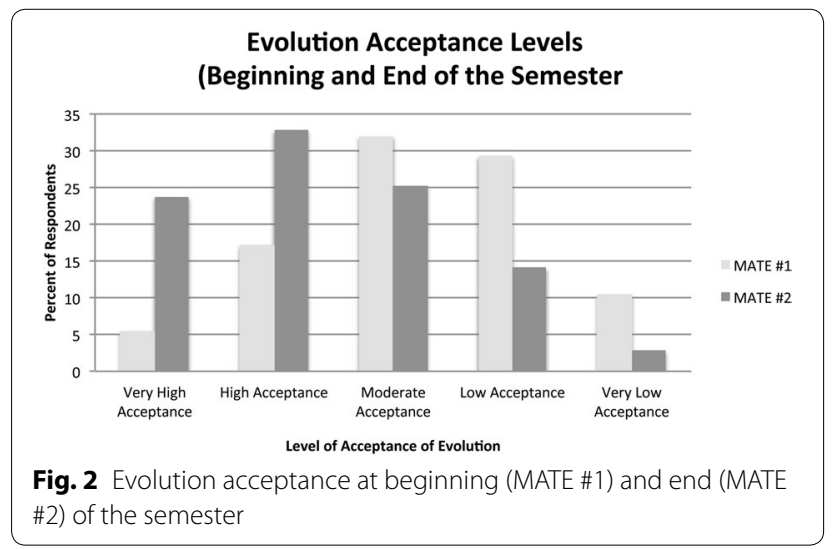

significant gains in knowledge of evolution regardless of religiosity Fig. 3.

\section{Is there a relationship between conceptual understanding of evolutionary theory and acceptance?}

Many have found a positive relationship between knowledge and acceptance of evolution (Wilson 2005; Ingram and Nelson 2006; Robbins and Roy 2007), while others have not (Lawson and Worsnop 1992; Crawford et al. 2005; Cavallo and McCall 2008). We found a positive relationship between knowledge of evolution and acceptance of evolution (see Table 3). In addition, as students with an incorrect or limited understanding gained 


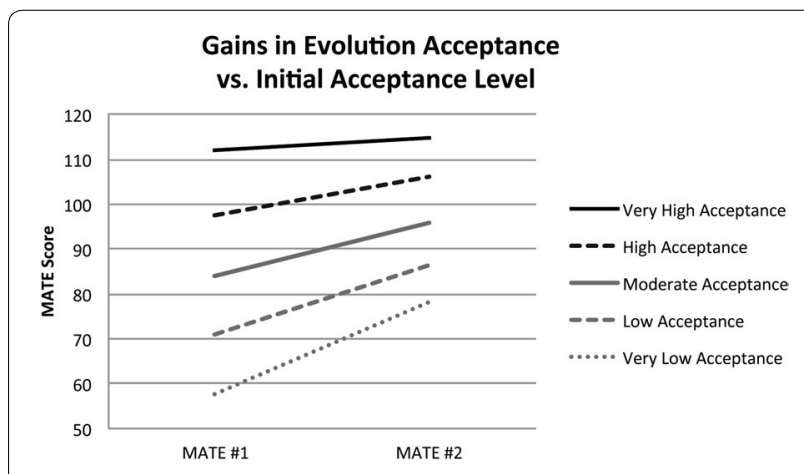

Fig. 3 Gains in evolution acceptance vs. initial acceptance level

greater competency with the theory of evolution (defined as being able to correctly comprehend major evolutionary tenets) they also became more accepting of it (see Fig. 1a, c).

\section{Is there a relationship between religious commitment (religiosity) and student acceptance of evolution?}

Our data show that religiosity does affect their initial willingness to accept evolution. We found a negative relationship between overall religiosity and acceptance of evolution (Table 3). The items used in our measure of religiosity (e.g., frequency of prayer, church attendance, belief in an afterlife, etc.; see Additional file 1: Appendix A) show that religiosity itself may be a causative factor in low acceptance of evolution. These findings are in line with numerous, previous research articles (e.g., Andersson and Wallin 2006; Coyne 2012; Heddy and Nadelson 2013; Rissler et al. 2014). Student religiosity did affect the initial acceptance rate of evolution (Table 3), but it did not hinder students from increasing in acceptance of evolution by the end of the semester. Students who were initially the least accepting of evolution had a significant increase in acceptance. We found that religiosity was a significant positive predictor $(p<0.001)$ of change in MATE and that the more religious an LDS individual ranked the greater the gains in acceptance of evolution over the course of the semester. Even though we used normalized gains to remove a ceiling effect, it should be noted that it may be that the most religious students were initially the least accepting of evolution and had the most to gain. Nevertheless, although religiosity is a factor in initial acceptance of evolution, it does not prevent LDS individuals from learning or modifying their views.

Does an understanding of LDS doctrine concerning evolution affect acceptance of evolution among LDS students? And Can instructors influence LDS student acceptance of evolution by helping them understand the specific religious doctrine on evolution?

One novel result from this study was that as students learned more about their own religion and its doctrine on evolution, acceptance rates increased significantly $(p<0.001)$. We found a positive relationship between student initial understanding of the LDS stance on evolution (ULSE) and initial acceptance of evolution (MATE; see Table 3).

We also found that as students with an incorrect or limited understanding of the LDS stance on evolution gained knowledge of LDS doctrine (via class discussion (Fig. 1b). Students who did not participate in a discussion had greater gains in knowledge of evolution but had significantly less gains in acceptance of it (see Fig. 1d). The more misconceptions a student harbored regarding the LDS stance on evolution the less likely they were to accept the theory of evolution. In the control class, students made significantly smaller gains in their understanding of LDS doctrine on evolution (ULSE; Fig. 1b, 1d). Not having a discussion focused on LDS doctrine could have impeded their ability to synthesize their understanding of evolution with LDS beliefs. Interestingly, Masci (2009) found that of the general US public, people who attend worship services more frequently are less likely to perceive faith and science as conflicting forces. In conjunction with Masci (2009), our results suggest that some factors leading to higher acceptance of science could be familiarity with one's religion (as long at the religion is neutral or supportive to evolution), intellectual engagement and/or theological engagement. We demonstrate that when students recognize that LDS doctrine is neutral towards evolution and are able to actively discuss this point in a classroom setting, they become empowered to form positive viewpoints on evolution.

Longitudinal surveys show that students from both semesters retained the same degree of acceptance of evolution 5-7 months following the end of class, while losing some knowledge of evolution. Nadelson and Sinatra (2010) showed that acceptance of evolution increases even when knowledge does not. We have shown that acceptance can be maintained even while knowledge decreases over time. This makes for potential concern as it seemingly produces students who have an ongoing favorable opinion/acceptance of evolution but cannot recall specific principles that support the theory. We speculate that students may not remember the details of what was being explained, but found the explanation compelling enough to increase their acceptance. Further, since the MATE questions focus on "big picture" ideas, it may be easier for students to retain impressions of the correctness of the theory 6 months later while not being able to remember the more detailed nuances assessed by 
the KEE. The cause for an increase in the KEE score during the semester could be due to extrinsic motivation to learn evolution in order to get a better grade while their motivation for accepting is likely only intrinsic. Therefore, once the semester is over the facts pertaining to evolution are quickly forgotten while the attitudes remain intact because education that takes place by intrinsic motivation leads to sustained learning (Ryan and Deci 2000).

It may seem surprising that MATE scores increased beyond the end of the semester. This is most likely due to response bias. Only 30.8 and $23.3 \%$ of the students that took the surveys during the winter 2013 and fall 2013 semesters, respectively, took the longitudinal surveys. While incentives were offered to students who took the longitudinal surveys (entrance into a drawing), those who actually completed it may have been those who had more interest in the topic. Interestingly, we found that students who initially had higher acceptance of evolution were more likely to participate in the longitudinal survey than those who initially had low acceptance of it $(\mathrm{p}<0.01)$.

Another interesting finding is that students seemed to retain knowledge of the LDS stance on evolution while forgetting specific knowledge of evolution. There are some limitations to this specific finding. The knowledge of the LDS stance on evolution was measured on a scale ranging from "strongly disagree" to "strongly agree," while knowledge of evolution was measured with a dichotomously scored test where they either got each question right or wrong. Since student responses on the knowledge they retained toward the LDS stance on evolution cannot be coded as right or wrong it is not possible to directly compare the retention of knowledge of the LDS stance on evolution with the retention of knowledge concerning evolution. However, we do find that knowledge of LDS doctrine remained while knowledge of evolution was lost.

Intriguingly, students who were not part of a discussion of LDS doctrine saw gains in knowledge of evolution that exceeded the treatment sections (Fig. 1c). A possible explanation for this is that students in the control section spent time learning biology content while their counterparts were discussion religion. These discussions took up to $75 \mathrm{~min}$, which is $3.6 \%$ of the total class time over the semester or $12.5-25 \%$ of the class time devoted to the unit on evolution. Other variables that may have influenced this greater gain in knowledge could be random sampling, instructor effect, or learning style.

We recognize there are other limitations to this study. Foremost, we understand that our conclusions were reached from an exclusively LDS population of students. The LDS church is unique in the way its worldwide congregations are united by and adhered to the same doctrine. However, this is also a benefit in such studies since attempting this same study among other religions would prove more difficult due to the variation between congregations and sects. Thus, the LDS population serves as a homogeneous representative sample of highly religious people. Despite any limitations of this study, the results and principles we found are compelling and lead to meaningful conclusions that can be applied to the classroom and future research.

\section{Conclusions}

Most student populations will have challenges, many unique, with accepting evolution. However, the challenges can be overcome with purposeful intervention, usually by creating cognitive dissonance for the students. For our study, we identified, diagnosed, and dealt with a barrier to evolution acceptance that was prevalent in our classrooms. Our student population had issues with accepting evolution due to lack of knowledge of their own religious doctrine, a challenge not unique to LDS students. At BYU, we were able to create a controlled environment to research this barrier and how to overcome it. We designed a meaningful intervention that led to significant increases in acceptance of evolution. Allowing LDS students to discuss and explore religious doctrine on evolution increased their willingness to accept it. We suggest that other educators struggling to help students understand or accept evolution can likewise find meaningful interventions to help overcome student reluctance toward evolution. One idea is for educators to allow students time in class to brainstorm what hesitations they have to accepting evolution, then direct them to research sources that support and contradict that hesitation. Whatever the intervention, we hope this gives instructors creative insight to how they may address barriers to evolution acceptance in their classroom.

For those educators interested in addressing the barrier of religion in evolution education, we assert that our results can likely be extended to other Christian denominations because the conflict between religion and evolution is relatively universal. We encourage educators to find ways for religious students to explore their respective religious doctrines towards evolution. We do not suggest that instructors necessarily take time out of class to discuss religion and science if they are not comfortable doing so or do not feel it appropriate for their students. However, we are suggesting that encouraging religious students to research their own religious doctrines may prove valuable to student acceptance of the theory of evolution. For example, a resource for students may be The Clergy Letter Project, which is a conglomeration of over 13,800 signatures from numerous clergymen (including Christian, Jewish, 
and Buddhist clergy) who endorse statements supporting the compatibility of religion and science (including evolution; Zimmerman 2010). For educators who teach students with potential religious barriers, this may be a helpful tool for students to overcome reservations they may have about learning evolutionary theory. We suggest that this model will hold with students claiming membership to other Christian religions, which also have a neutral or favorable stance on the theory of evolution.

\section{Additional file}

Additional file 1: Appendix. Surveys administered to undergraduate students as part of this research and BYU's mission statement.

\section{Abbreviations}

BYU: Brigham Young University; KEE: knowledge of evolution exam; LDS: The Church of Jesus Christ of Latter-day Saints; MATE: measure of acceptance of the theory of evolution; ULSE: understanding of the LDS stance on evolution.

\section{Authors' contributions}

KFM designed the research plan, gathered data, complete all analyses, and drafted the manuscript. SMB and JЈJ helped to conceive the research, chose the original surveys for this research (including drafting one of the surveys), aided in data interpretation, and critically revised the manuscript. RAG also aided in data interpretation and making critical revisions to the manuscript. Instrument questions were revised and additional items were added by KFM. All authors read and approved the final manuscript.

\section{Authors' information}

KFM is a PhD candidate. SMB and JLJ are Assistant Professors, RAG is an Associate professor. All are affiliated with Brigham Young University.

\section{Acknolwedgements}

We would like to thank the BYU IRB for support in research and teachers in the college life sciences at BYU for allowing us to distribute surveys to their students. We thank Qualtrics for providing the platform for survey distribution, Kelsy Johnson and Brook Viiga for data input, and Richard Sudweeks for help in data analyses. We thank the Bybee and Jensen labs as well as reviewers for extensive help in revising this manuscript. This research was funded by a McKay Award from Brigham Young University to SMB and JLJ) and NSF grant to SMB (DEB-1265714).

\section{Competing interests}

The authors declare that they have no competing interests.

Received: 19 August 2015 Accepted: 25 November 2015

Published online: 03 December 2015

\section{References}

Affirmation of Creation. Official statements. http://www.adventist.org/information/official-statements/statements/article/go/0/affirmation-of-creation/. (2004). Accessed 17 Dec 2014.

Akyol G, Tekkya C, Sungur S. The contribution of understanding of evolutionary theory and nature of science to pre-service teachers' acceptance of evolutionary theory. Procedia Soc Behav Sci. 2010;9:1893-9.

Anderson DL, Fisher KM, Norman GJ. Development and evaluation of the conceptual inventory of natural selection. J Res Sci Teach. 2002;39(10):952-78.

Andersson B, Wallin A. On developing content-oriented theories taking biological evolution as an example. Int J Sci Educ. 2006;28(6):673-95.
Andrews TM, Price RM, Mead LS, McElhinny TL, Thanukos A, Perez KE, Herreid CF, Terry DR, Lemons PP. Biology undergraduates' misconceptions about genetic drift. Life Sci Educ. 2012;11:248-59.

Athanasiou K, Mavrikaki E. Conceptual inventory of natural selection as a tool for measuring Greek university students' evolution knowledge: differences between novice and advanced students. Int J Sci Educ. 2013;36(8):1262-85.

Barnes RM, Keilholtz LE, Alberstadt AL. Creationism and evolution beliefs among college students. Skeptic. 2009;14(3):13-6.

Battisti BT, Hanegan N, Sudweeks R, Cates R. Using item response theory to conduct a distracter analysis on conceptual inventory of natural selec tion. Int J Sci Math Educ. 2010;8(5):845-68.

Brewer MS, Gardner GE. teaching evolution through the hardy-weinberg principle: a real-time, active-learning exercise using classroom response devices. Am Biol Teach. 2013;75(7):476-9.

Burton EK. Evolution and creationism in middle eastern education: a new perspective. Evolution. 2011;65(1):301-4.

Carter BE, Wiles JR. Scientific consensus and social controversy: exploring relationships between students' conceptions of the nature of science biological evolution, and global climate change. Evol Educ Outreach. 2014;7(1):6.

Cavallo AM, McCall D. Seeing may not mean believing: examining students' understandings and beliefs in evolution. Am Biol Teach. 2008;70(9):522-30.

Colburn A, Henriques L. Clergy views on evolution, creationism, science, and religion. J Res Sci Teach. 2006;43(4):419.

Cotner S, Brooks DC, Moore R. "Is the age of the earth one of our "sorest troubles?" Students' perceptions about deep time affect their acceptance of evolutionary theory. Evolution. 2010;64(3):858-64.

Coyne JA. Science, religion, and society: the problem of evolution in America. Evolution. 2012;66(8):2654-63.

Crawford BA, Zembal-Saul C, Munford D, Friedrichsen P. Confronting prospective teachers' ideas of evolution and scientific inquiry using technology and inquiry-based tasks. J Res Sci Teach. 2005;42(6):613-37.

Foster C. Creationism as a Misconception: socio-cognitive conflict in the teaching of evolution. Int J Sci Educ. 2012;34(14):2171-80.

Grant HJ, Ivins AW, Nibley CW. Mormon View of Evolution. Salt Lake City: The Church of Jesus Christ of Latter-day Saints; 1925.

Ha M, Haury DL, Nehm RH. Feeling of certainty: uncovering a missing link between knowledge and acceptance of evolution. J Res Sci Teach. 2012;49(1):95-121.

Hafiz, Y. America's most and least religious colleges. The Huffington Post, Online. http://www.huffingtonpost.com/2014/08/06/most-least-religious-colleges-usa_n_5649242.html. (2014). Accessed 22 June 2015.

Halverson KL. Using pipe cleaners to bring the of life to life. Am Biol Teach. 2010;72(4):223-4.

Hawley PH, Short SD, McCune LA, Osman MR, Little TD. What's the matter with Kansas?: the development and confirmation of the Evolutionary Attitudes and Literacy Survey (EALS). Evol Educ Outreach. 2011;4(1):117-32.

Heddy BC, Nadelson LS. The variables related to public acceptance of evolution in the United States. Evolution. 2013;6(1):3.

Ingram EL, Nelson CE. Relationship between achievement and students' acceptance of evolution or creation in an upper level evolution course. J Res Sci Teach. 2006;43(1):7-24.

Kahan DM. Climate-science communication and the measurement problem. Political Psychol. 2015;36(S1):1-43.

Kim SY, Nehm RH. A cross-cultural comparison of Korean and American science teachers' views of evolution and the nature of science. Int J Sci Educ. 2011;33(2):197-227.

Kohut A, Keeter S, Doherty C, Dimock M. Scientific achievements less prominent than a decade ago: public praises science; scientists fault public, media. Washington, DC: The Pew Research Center for the People \& the Press; 2009.

Lawson AE, Worsnop WA. Learning about evolution and rejecting a belief in special creation: effects of reflective reasoning skill, prior knowledge, prior belief and religious commitment. J Res Sci Teach. 1992;29(2):143-66.

Ludlow DH. Evolution. In: Ludlow DH, editor. Encyclopedia of Mormonism. New York: Macmillan; 1992.

Masci D. Public opinion on religion and science in the United States. Washington, DC: Pew Research Center; 2009. http://www.pewforum.org/2009/11/05/ 
public-opinion-on-religion-and-science-in-theunited-states/. Accessed 15 June 2015

Mayr E. What evolution is. New York: Basic books; 2001.

McKenna J. Pope Francis: 'Evolution...is not inconsistent with the notion of creation'. Religious New Service. Online: http://www.religionnews. com/2014/10/27/pope-francis-evolution-inconsistent-notion-creation/. Accessed Jan 2015

Meadows L, Doster E, Jackson DF. Managing the conflict between evolution and religion. The Am Biol Teach. 2000;62:102-7.

Miller JD, Scott EC, Okamoto S. Public acceptance of evolution. Science. 2006;313(5788):765

Miller T. U.S.Religious landscape survey: religious beliefs and practices: diverse and politically relevant. Washington, DC: The Pew Forum on Religion \& Public Life; 2008. p. 95-7.

Mislin D. According to his own judgment: the American catholic encounter with organic evolution, 1875-1896. Relig Am Cult-A J Interpret. 2012:22(2):133.

Moore R, Brooks C, Cotner S. The relation of high school biology courses \& students' religous beliefs to college students' knowledge of evolution. The Am Biol Teach. 2011;73(4):222-6.

Nadelson LS, Sinatra GM. Shifting acceptance of evolution: Promising evidence of the influence of the "understanding evolution" website. The Res. 2010;23(1):13-29.

Nehm RH, Schonfeld IS. Does increasing biology teacher knowledge of evolution and the nature ofscience lead to greater preference for the teaching of evolution in schools? J Sci Teach Educ. 2007;18(5):699-723.

Newport F. In US, 46\% hold creationist view of human origins. Gallup Politics; 2012

Price RM, Andrews TC, McElhinny TL, Mead LS, Abraham JK, Thanukos A, Perez KE. The genetic drift inventory: a tool for measuring what advanced undergraduates have mastered about genetic drift. Life Sci Educ. 2014;13:65-75.

Rees PA. The evolution of textbook misconceptions about Darwin. J Biol Educ. 2007;41(2);53-5

Reiss MJ. The relationship between evolutionary biology and religion. Evolution. 2009;63(7);1934-41.

Religious Groups'Views on Evolution. Washington, DC: Pew Research Center; 2009. http://www.pewforum.org/2009/02/04/religious-groups-views-onevolution/. Accessed Dec 2013.
Rissler LJ, Duncan SI, Caruso NM. The relative importance of religion and education on university students' views of evolution in the Deep South and state science standards across the United States. Evolution Educ Outreach. 2014;7(1):24.

Robbins JR, Roy P. The natural selection: Identifying and correcting nonscience student preconceptions through inquiry-based, critical approach to evolution. The Am Biol Teach. 2007;69(8):460-6.

Rutledge ML, Sadler KC. Reliability of the measure of acceptance of the theory of evolution (MATE) instrument with university students. The Am Biol Teach. 2007;69(6):332-5.

Ryan RM, Deci EL. Intrinsic and extrinsic motivations: classic definitions and new directions. Contemp Educ Psychol. 2000;25:54-67.

Sherkat DE. Religion and scientific literacy in the United States. Soc Sci Q. 2011;92(5):1134-50.

Smith JF, Lund AH, Smith JH. Words in season from the first presidency. In: Deseret evening news. Salt Lake City, Utah, The Church of Jesus Christ of Latter-day Saints; 1910. p. 3.

Smith JF, Winder JR, Lund AH. The origin of man. In: The improvement era. vol. 13. Salt Lake City, Utah, The Church of Jesus Christ of Latter-day Saints; 1909. p. 75-81.

Wagler A, Wagler R. Addressing the lack of measurment invariance for the measure of acceptance of the theory of evolution. Int J Sci Educ. 2013;35(13):2278-98.

Wiles JR, Alters B. Effects of an educational experience incorporating an inventory of factors potentially influencing student acceptance of biological evolution. Int J Sci Educ. 2011;33(18):2559-85.

Wiles JR. Students' perceptions of their acceptance of evolution, changes in acceptance, and factors involved therein. Evolution: Educ Outreach. 2014;7(4). doi:10.1186/s12052-014-0004-5.

Wilson DS. Evolution for everyone: how to increase acceptance of, interest in, and knowledge about evolution. PLoS Biol. 2005;3(12):e364. doi:10.1371/ journal.pbio0030364.

Weeks L. Unraveling the myth of evolution. J South Baptist Conv. 1999.

Zimmerman M. The clergy letter project. http://www.theclergyletterproject. org/rel_evol_sun.htm. Accessed 15 June 2015.

\section{Submit your manuscript to a SpringerOpen ${ }^{\odot}$ journal and benefit from:}

- Convenient online submission

- Rigorous peer review

- Immediate publication on acceptance

- Open access: articles freely available online

- High visibility within the field

- Retaining the copyright to your article

Submit your next manuscript at $>$ springeropen.com 